DOI: 10.24867/MD.9.2017.2.57-60

Research paper

\title{
CLAMPING AND SUSPEND SYSTEMS TO MANIPULATIONS DOCKING RAMPS
}

Vasile ALEXA $1,{ }^{*}$ - Sorin RATIU1

${ }^{1}$ Politehnica University of Timişoara, Faculty of Engineering Hunedoara, Hunedoara, Romania

Received (13.05.2016); Revised (14.09.2016); Accepted (19.09.2016)

Abstract: This paper presents a comparative analysis of two proposed solutions to achieve the handling and transport platforms docking. The proposed solutions are analyzed by finite element method and validated by laboratory experiments. The solution adopted will be chosen according to the chosen transport equipment.

Key words: finite element, lifting eyes, safety factor

\section{INTRODUCTION}

Any equipment, any construction element must be equipped with one or more devices suitable for transportation. Only in this way can during each stage of production, assembly, delivery (by train or truck), final assembly at the customer, speed ferry optimal conditions with maximum safety for staff and fixture construction. Attachment points - an absolute necessity that does not give importance to many builders.

In the next table (Table 1) shows the main mounting schemes of different assemblies depending on their weight and shape [1].

Table 1. The main mounting schemes

\begin{tabular}{|c|c|c|c|c|c|}
\hline Scheme & $\begin{array}{c}\text { Number } \\
\text { of arms }\end{array}$ & $\begin{array}{c}\beta \\
{\left[{ }^{0}\right]}\end{array}$ & Scheme & $\begin{array}{l}\text { Number } \\
\text { of arms }\end{array}$ & $\begin{array}{c}\beta \\
{\left[{ }^{0}\right]} \\
\end{array}$ \\
\hline G & 1 & 0 & & 2 & $0-45$ \\
\hline$\overline{\delta^{A}}$ & 2 & 0 & & $3-4$ & $45-60$ \\
\hline G & 1 & 90 & $\mathbf{G}$ & $3-4$ & $0-45$ \\
\hline G & 2 & 90 & & $3-4$ & $45-60$ \\
\hline
\end{tabular}

Means used to loading - unloading, transshipment goods transported adapters are selected according to the following criteria [2]:

- nature of the goods to be transported (solids or liquids, acids or bases, with or without risk of damage;

- shape and size of elements (in bulk chunks or small, heavy or bulky granular or powdery state, etc.);

- of packing (bags, packages, bottles, containers, etc.);

- how to place the deposit (in piles, stacks, palletized or not, etc.);

- type of means of transport to be achieved;

- the quantity of goods handled per unit time.
Frequently transported objects are equipped with threaded holes for all screws ring DIN. When you want to use very resistant screw attachment points, these holes are usually oversized and require the use of fixings too high [3].

Accessories and devices for catching and suspending pregnancy are built in a variety constructive handled by load characteristics and handling mechanism. Here are some examples (Figure 1) [4]:
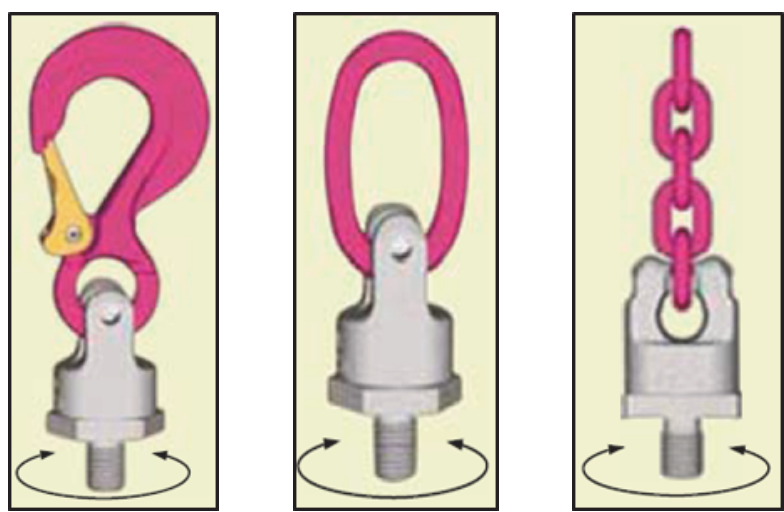

Fig.1. Lifting eyes models

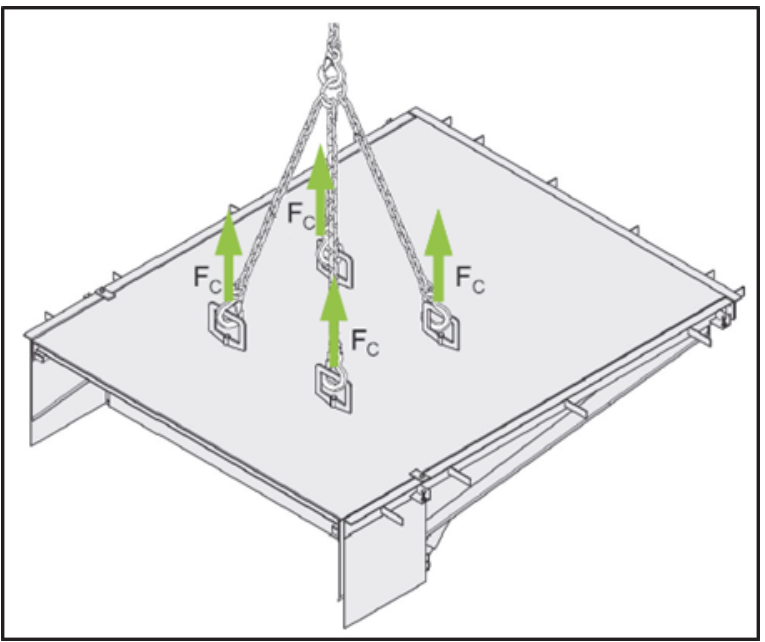

Fig.3. Transport case-using a crane 
Most often using screws DIN 580 ring of C15 or predict construction sheet which do not allow the possibility of load angle respectively are usually oversized so that smaller hooks opening and flap safety cannot be caught. Docking ramp handling the manufacture, transport, installation and facilities according to of the economic agent can be done using overhead cranes (Figure 2) or a forklift (Figure 3).

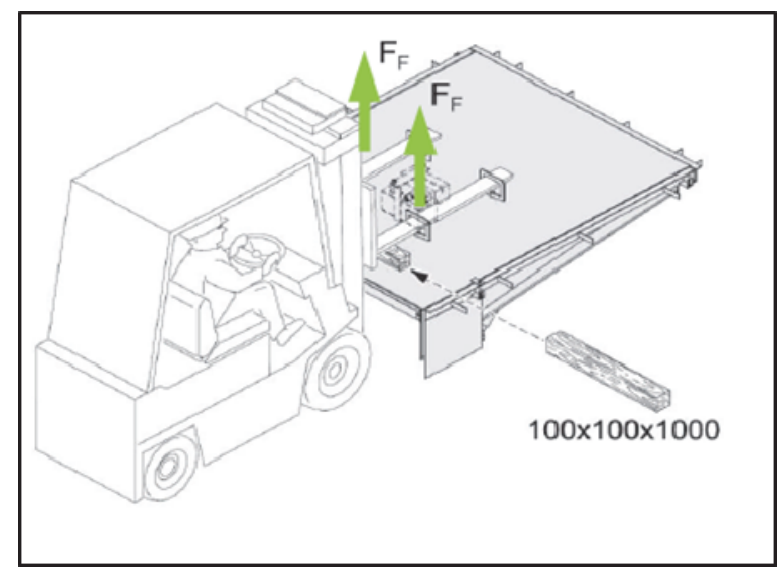

Fig.4. Transport case-using a lifting

In this case, fixing and fastening systems have an important role due primarily to ensure the safety of workers and secondly is affected finished product quality by eliminating non-conformities.

In both cases should be considered gauge assembly to handle its geometrical shape and the binding mode of high load.

Loading gauge assembly docking ramp is different, depending on the type of ramp is designed and respectively its additional facilities $[5,6,7]$.

Fixing and fastening system also has a very important role because it influences the production costs of both the manufacturing company and the beneficiary dock ramps.

\section{THE PROPOSED CONSTRUCTIVE SOLUTIONS FOR FASTENING SYSTEMS AND HANDLING OF DOCKING RAMPS}

Given the above, we propose finding a technical solution to solve the problems faced by the manufacturer of the docking ramps manufacturer.

Like the initial starting date, we will consider two aspects:

- weights and dimensions to the docking ramps transported;

- the transport equipment used.

The main types of docking ramps carried out the following sizes shown in Table 2 .

Special problems are caused by handling and transport using fork, given the typical geometric constructive and its forks, presented suggestive in Figure 5.

For the two types of equipment used to transport, we consider two constructive solutions for fixing and manipulating dock ramps, shown in Figure 6 and Figure 7.
Table 2. The main types of docking ramps

\begin{tabular}{|c|c|}
\hline Type & Mass \\
\hline SD 610 2500x2000x700 & 780 \\
\hline SD 610 3000x2000x700 & 870 \\
\hline TD 620 2500x2000x700 & 950 \\
\hline TD 620 3000x2000x800 & 1250 \\
\hline LHT $100 \mathrm{kN} 3000 \times 2000 \times 800$ & 1750 \\
\hline
\end{tabular}
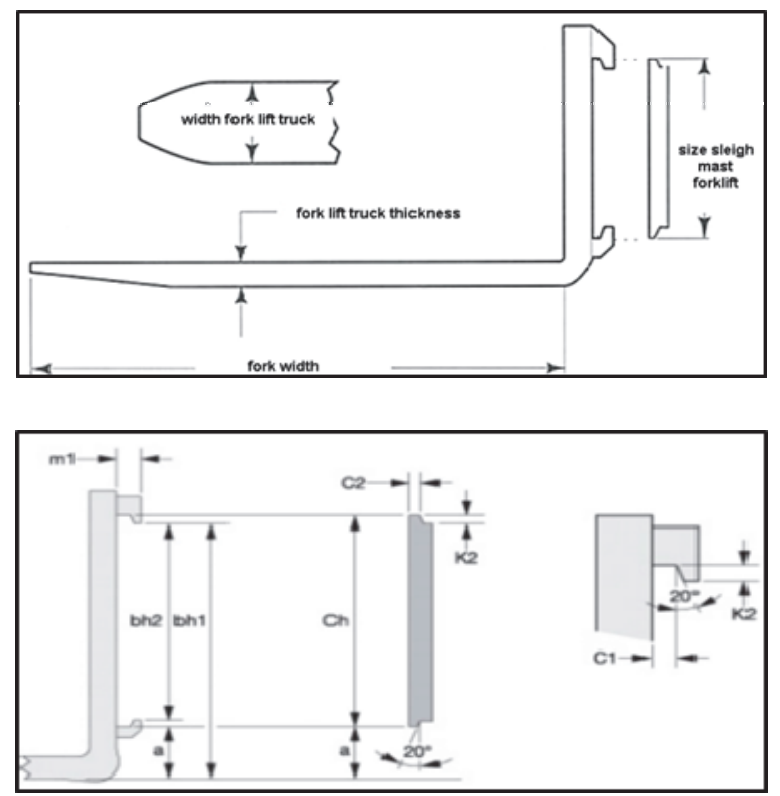

Fig.5. Fork lift truck-geometrical parameters
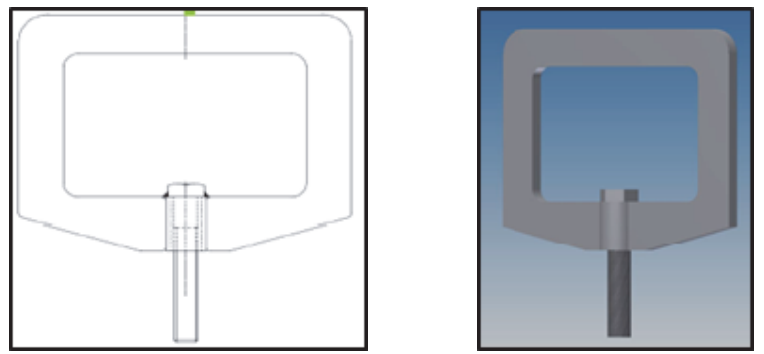

Fig.6. Fork lift truck-variant 1 - geometrical parameters
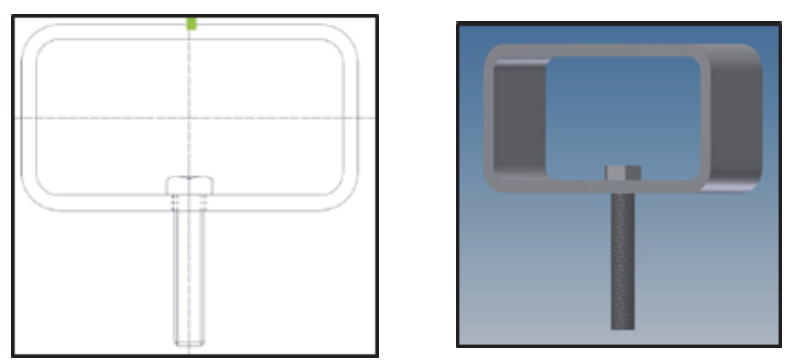

Fig.7. Fork lift truck-variant 2 - geometrical parameters 
Axial force an a single lifting eye, according to the charts, when lifting a leveler with load $\mathrm{G}$ of charge for two types of transport used data handling relations:

- using crane: in this situation, for a single lifting eyes action load $\frac{G}{4}$ and is $\beta=45^{\circ}$ :

$$
F_{C}=\frac{G}{4} \sin \beta=0.176 G
$$

- using forklift: in the worst scenario, when lifting only with two lifting eyes, axial force have value:

$$
F_{F}=0.75 G
$$

\section{ANALYSIS OF THE TWO PROPOSED SOLUTIONS}

Based on the two proposed solutions, but also from the two means of handling and transport used make a pertinent analysis on their behavior in exploitation, analysis summarized in Table 3.

Table 3. Maximum leveler weight

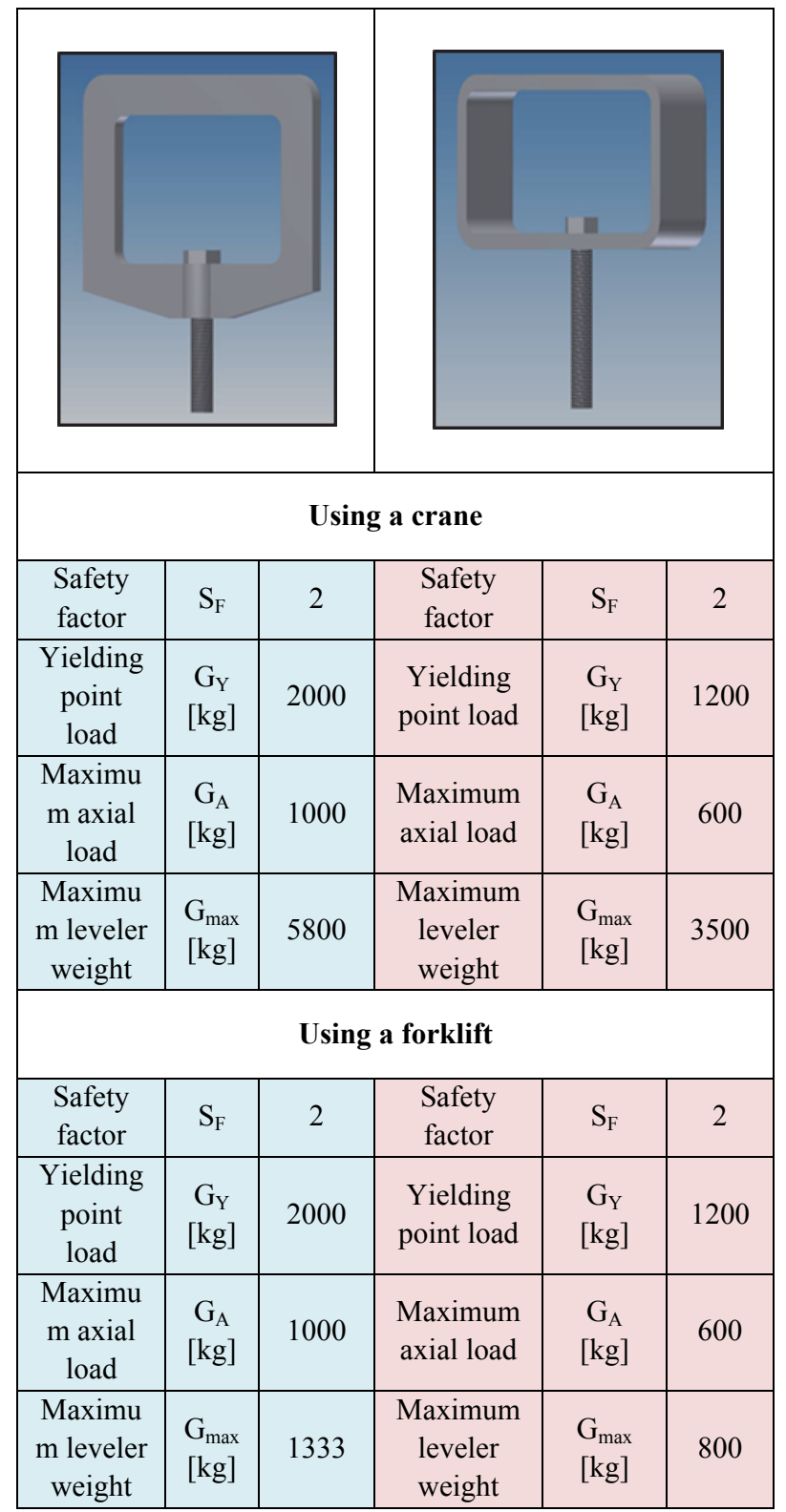

Using machines tried to the traction have tried two fasteners and lifting proposed to square axial force-strain diagram, Figure 8 and Figure 9.

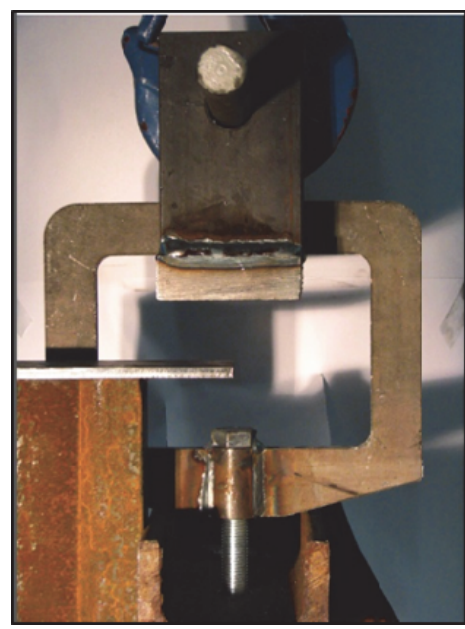

Fig.8. Fork lift truck-geometrical parameters

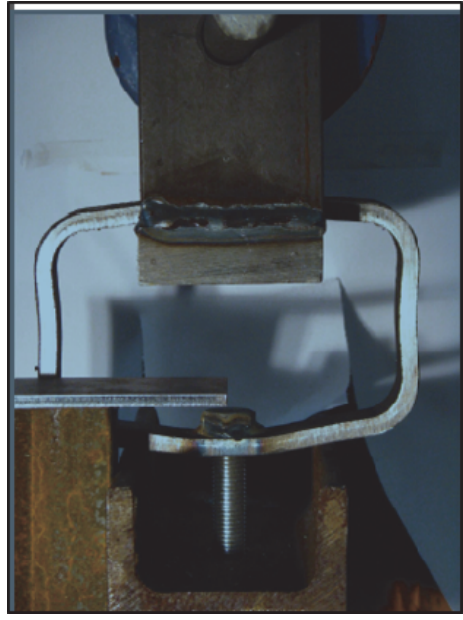

Fig.9. Fork lift truck-geometrical parameters

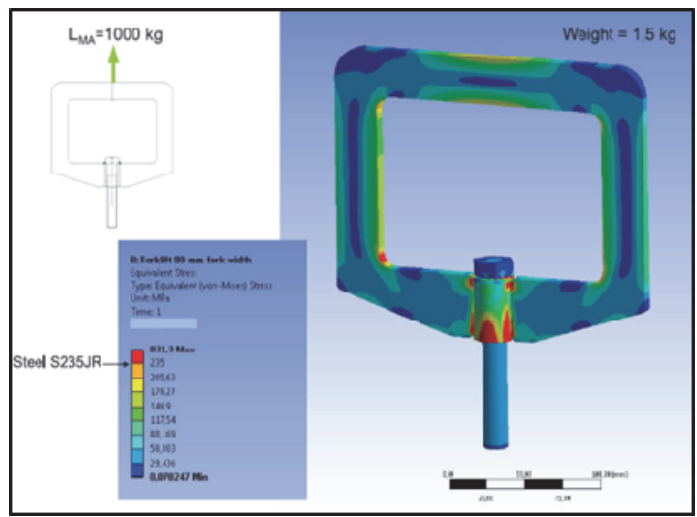

Fig.10. Virtual model 1-FEA

In order to take into account the test conditions and fastening systems proposed lifting was carried out a simulation using ANSYS Mechanical software package Strength Analysis.

It has been observed that both the elastic and plastic behavior of real fasteners and lifting is approximately equal studied virtual behavior. 


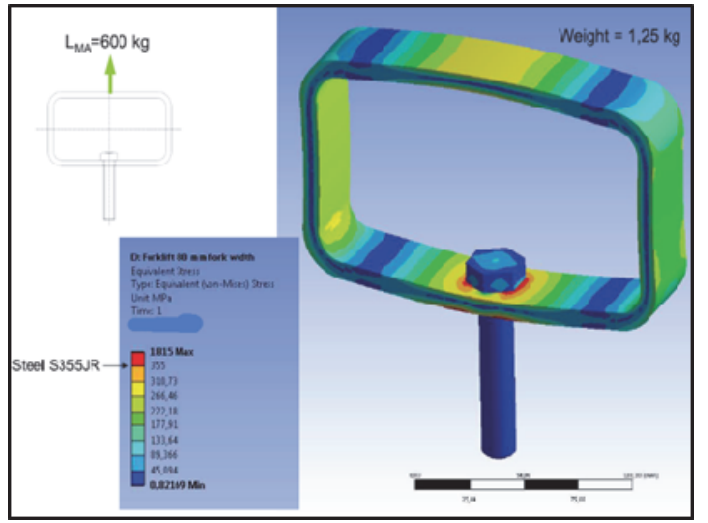

Fig.11. Virtual model 2 - FEA

Among the proposed option 1 (Figure 6) and version 2 (Figure 7) observed that the two provides greater resistance resulting in further dimensional rethinking of this embodiment, Figure 12.

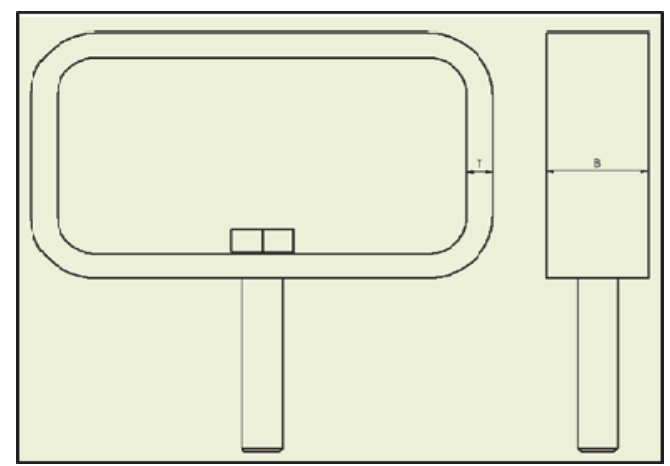

\begin{tabular}{|c|c|c|}
\hline $1-B x T-35 \times 8$ & 4-BxT-40x8 & 7-BxT-50x8 \\
\hline $2-B \times T-35 \times 10$ & $5-\mathrm{BxT}-40 \times 10$ & $8-B \times T-50 \times 10$ \\
\hline $3-B \times T-35 \times 12$ & 6-BхT-40x12 & 9-BxT-50x12 \\
\hline
\end{tabular}

Fig.12. Dimensional variations considered

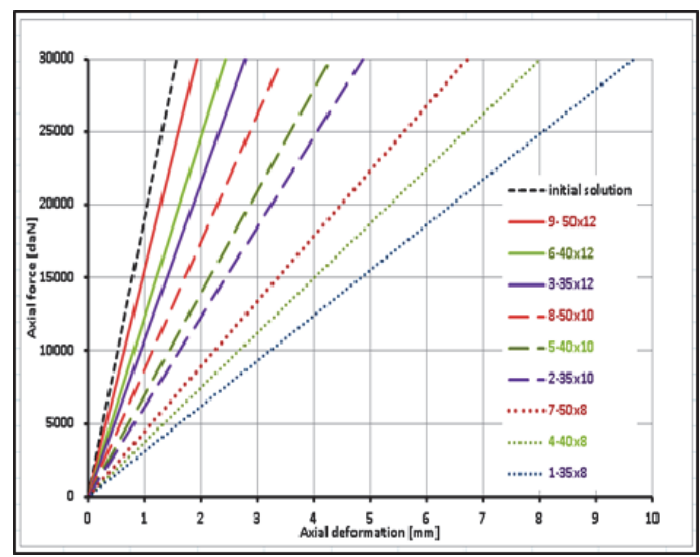

Fig.13. Graph axial deformation-axial force
For the nine proposed dimensional variations were performed tensile testing, resulting graph in the figure below (Figure 13).

\section{RESULTS AND CONCLUSIONS}

While contribute through the implementation of attachment point, which provides safety to:

- minimize the risk of accidents!

- preventing damage and downtime!

- reducing transshipment times!

After analyzing virtual model proposed were identified following:

- increasing width from 35 to $40 \mathrm{~mm}$ to increase the resistance factor of 1.1, and an increase in the width of 40 to $50 \mathrm{~mm}$, the same resistance factor from 1.4 increases.

- increasing the thickness of 8 to $10 \mathrm{~mm}$ to increase the resistance factor of 2, and an increase in the thickness of 10 to $12 \mathrm{~mm}$, the same resistance factor increased to 3.4 .

The optimal variant is the variant 5 (40 x 12), increasing the resistance coefficient of 3.9 .

Compared to the version originally proposed, the new version has the following advantages: weight without screw is $1.8 \mathrm{~kg}$ and unit cost it is 2.8 euro (initial cost was 4 euro).

\section{REFERENCES}

[1] Alcaz, T., ş.a, (2007). Tehnologia organizării transportului de mărfuri, Universitatea Tehnică a Moldovei, Chişinău.

[2] Tezec, I. (2008). Proiectarea sistemelor de transport in transportul de marfă, Universitatea Tehnică a Moldovei, Chişinău.

[3] Herman, M. (2007). Sisteme şi mijloace de transport şi manipulare, Editura MIRTON.

[4] http://www.thecrosbygroup.com/

[5] http://web.rud.com/en-au/home.html

[6] http://www.hoermann.de/

[7] http://www.crawfordhafa.ro/

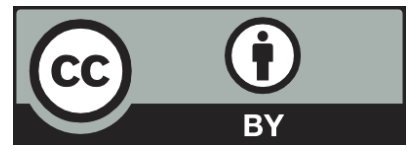

(C) 2017 Authors. Published by the University of Novi Sad, Faculty of Technical Sciences.

This article is an open access article distributed under the terms and conditions of the Creative Commons Attribution license 3.0 Serbia (http://creativecommons.org/licenses/by/3.0/rs/). 